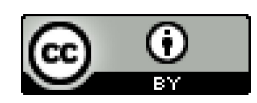

Esta obra está sob o direito de Licença Creative Commons Atribuição 4.0 Internacional.

\title{
PORTADORES DE DISLEXIA COM DIFICULDADES DE APRENDIZAGEM
}

Aracy Felix Silva ${ }^{1}$

\section{RESUMO}

O objetivo desse artigo, por meio de uma revisão da literatura é investigar o processo ao qual um indivíduo com dislexia sofre em seu processo de aprendizagem. É notório o avanço da ciência sobre as causas da dislexia, especialmente na neuropsicologia, e no funcionamento anátomo funcional. Grande parte das dificuldades com as quais as crianças disléxicas se deparam ocorre no âmbito da palavra individual, tal estudo tem implicações nas abordagens terapêuticas, essa desconstrução possibilita entendermos a divisão do que é ser "normal" do patológico.

Palavras-chave: Dislexia. Leitura. Anátomo funcional. Aprendizagem.

Submetido em dezembro de 2019 e aceito em janeiro de 2020.

\footnotetext{
${ }^{1}$ Pós Graduando do Curso de Neuropsicopedagogia com ênfase em saúde mental da FG Faculdades - Porto Alegre RS, aracyfelixs@gmail.com.
} 


\section{INTRODUÇÃO}

Em 1896, um menino de 14 anos de idade chamado Percy, instigado por sua dificuldade para aprender a ler e a escrever, consultou um médico e lhe disse que, embora fosse inteligente, não conseguia aprender a ler e escrever. Esse menino não sabia o alfabeto e apresentava erros ao grafar as palavras. $\mathrm{O}$ médico que o atendeu foi o inglês Pringle Morgan que, verificando suas dificuldades, apesar de ter visão normal, diagnosticou-o como portador de "cegueira verbal congênita", marcando o surgimento da categorização de um distúrbio de aprendizagem - a dislexia como patologia resultante de lesão cortical. Tal diagnóstico, porém, foi influenciado por estudos realizados com adultos que apresentavam transtornos na escrita, após sofrerem uma lesão cortical localizada, conforme Quirós e Della Cella (1972).

A dislexia é considerada como um distúrbio ou apresentação de dificuldades na aprendizagem e na linguagem, entendimento das palavras, da escrita, a soletração, assim como a compreensão e interpretação de textos e de atividades que envolvem o raciocínio lógico, de modo geral, a dislexia tem sido classificada de duas maneiras: a dislexia de desenvolvimento e a dislexia adquirida.
Este artigo visa esclarecer o processo de desenvolvimento e dificuldade de aprendizagem, segundo a revisão literária que será discutido mais à frente. Segundo a Associação Brasileira de Dislexia, o distúrbio é mais frequente nos homens, dados mostram que uma mulher para cada quatro homens pode ter dislexia, acomete de $0,5 \%$ a $17 \%$ da população mundial, pode manifestar-se em pessoas com inteligência normal ou mesmo superior e persistir na vida adulta.

Os sintomas variam de acordo com os diferentes graus de gravidade do distúrbio e tornam-se mais evidentes durante a fase da alfabetização. Entre os mais comuns encontram-se as dificuldades para ler, escrever e soletrar; de entendimento do texto escrito; identificar fonemas, associá-los às letras e reconhecer rimas e aliterações; para decorar a tabuada, reconhecer símbolos e conceitos matemáticos (discalculia); ortográficas: troca de letras, inversão, omissão ou acréscimo de letras e sílabas (disgrafia); de organização temporal e espacial e coordenação motora.

Há concordância na literatura de que grande parte das dificuldades com as quais as crianças disléxicas se deparam ocorre no âmbito da palavra individual, em particular na aquisição de habilidades automáticas de reconhecimento de palavras, o que altera a 
leitura fluente (Byrne, 1998). Por isso, crianças com dificuldades de leitura são mais dependentes do contexto do material lido. Essa dependência pode ser, em parte, um modo de compensar habilidades menos proficientes de reconhecimento de palavras (PERFETTI,1992).

A concepção científica da leitura deficiente predominante nos dias atuais é,

\section{METODOLOGIA}

A metodologia de pesquisa utilizada foi uma revisão de literatura tradicional, não sistemática, de caráter exploratório e qualitativo. Fez-se necessária leitura, análise e interpretação de livros, periódicos,

\section{RESULTADOS E DISCUSSÕES}

\section{Tipos de dislexia}

Há vários tipos de dislexia, a mais frequente entre as crianças disléxicas é a auditiva ou fonética, que ocorre devido a carência de percepção dos sons, o que acomete também as dificuldades com a fala, nessa leitura o indivíduo observa as palavras de uma forma global, deduzindo apenas as conhecidas, apresentam dificuldades na diferenciação, na análise e na nomeação dos sons da fala. Estão sujeitas a apresentarem problemas de memória, dificuldade em colocar pensamento em palavras, pronúncia incorretamente portanto, uma concepção em termos de déficit no processamento fonológico (WAGNER E TORGESEN, 1987). Este artigo mostra como a desconstrução de uma patologia implica na visão que temos sobre um sujeito em si, entre o que é ser normal na aquisição da escrita e/ou interpretação de textos do patológico.

textos legais e documento disponíveis em bibliotecas físicas e virtuais. Duas categorias temáticas foram obtidas a partir da análise dos documentos, a saber: tipos de dislexia; a avaliação e o processo neuropsicológico da aprendizagem infantil.

palavras longas ou transpõe frases, palavras e silabas ao falar.

As crianças com dislexia visual apresentam dificuldades sobretudo nas tarefas de percepção e discriminação visual, parecem ter problemas com a visão, mas exames oculares não revelam nenhum. Tendem a erros de orientação, problemas de discriminação de tamanhos e formas, confusões entre grupos de letras e dificuldades em transformar letras em sons, para além disso, apresenta ainda graves problemas em relação à ortografia e no reconhecimento de certas palavras que se pronunciam de forma diferente da escrita. Quando existe a combinação de mais de um 
tipo de dislexia, cujo nome é dado de dislexia mista, a dificuldade das crianças verifica-se tanto na análise fonética das palavras como na percepção de letras e palavras completas.

A dislexia do desenvolvimento é associada a disfunção cerebral, de base congênita, que sofre influências do meio, acometendo as bases subcorticais e corticais, alguns autores também consideram os fatores genéticos como umas das causas da dislexia do desenvolvimento. Até o século XIX, as informações e pesquisas que se tinham a respeito da sua patologia, ofereciam poucas evidências de bases biológicas e poucas informações sobre os processos de leitura da criança disléxica.

Esse quadro somente se modificou no final do século XX, em decorrência do desenvolvimento de técnicas de exame eletrofisiológicas e de neuroimagem, que levaram a elaboração de modelos teóricos e permitiram a obtenção de um maior conhecimento sobre as alterações anátomo funcionais presentes em indivíduos com dislexia, bem como a melhor compreensão sobre as vias cerebrais relacionadas ao processo de consciência fonológica, fundamental para o desenvolvimento da fala, leitura e escrita (KAJIHARA, 2008.).

Para que o processo da leitura e escrita ocorra de forma eficiente é necessário que as áreas cerebrais responsáveis pelo desenvolvimento dessas habilidades estejam em correto funcionamento e de forma integrada, visto que o processo da leitura requer, de sistemas sensoriais, motores além de aspectos neurológicos, psicológico, socioculturais dentre outros. Existem três caminhos neurais para a leitura: parietotemporal (responsável pela análise das palavras), frontal e occiptotemporal (responsável pela forma das palavras). Os dois primeiros são considerados "caminhos lentos", sendo utilizados principalmente por leitores iniciantes; e o último é considerado um “caminho rápido", utilizado por leitores mais experientes (DEUSCHLE E CECHELLA, 2009), em indivíduos com dislexia as partes anterior e posterior do cérebro, há uma subativação de caminhos neurais da parte posterior e uma superativação da parte anterior do cérebro.

Como consequência, a falha nos sistemas posteriores impede o reconhecimento rápido e automático das palavras e o desenvolvimento do lado direito e da parte anterior como sistema compensatório, permite que haja uma leitura precisa, porém mais lenta. Estes resultados sustentam a conclusão de que o prejuízo na dislexia fonológica é anátomo funcional e que esses padrões de ativação cerebral podem fornecer uma assinatura neural para esta deficiência (SHAYWITZ, 2002). 


\section{A avaliação e $\quad$ o $\quad$ processo neuropsicológico da aprendizagem infantil}

A aprendizagem é definida como uma mudança de comportamento resultante de prática ou experiência anterior. Devido ao fato da aprendizagem ser constituída por processos neurais é de grande valia fazer uso dessa ferramenta de estudo para compreender esse processo, dado que alterações nesses processos resultam em transtornos de aprendizagem, compreendendo $\mathrm{o}$ funcionamento intelectual do indivíduo, o uso de instrumentos para uma intervenção e melhoria na aprendizagem da criança, se torna mais eficaz.

A aprendizagem é um processo contínuo, que opera sobre todos os dados que alcançam um umbral de significação, dependendo, essencialmente, da memória e da atenção. A capacidade de especialização cerebral em armazenar dados ('engramas') para a sua utilização posterior permite, mediante a memória, codificar e decodificar informação; existem vários tipos de memória (sensorial, curto prazo ou de trabalho, e longo prazo) que podem trabalhar, não só sequencialmente, mas também em paralelo, dependente basicamente da plasticidade sináptica.

Atenção permite focalizar atividades conscientes dependentes de sistemas e subsistemas anátomo-funcionais, que trabalham como redes em paralelo, permitindo uma atuação simultânea e interativa nas tarefas cognitivas (CORREIA E CAMPOS, 2000). A aprendizagem infantil, no que tange ao processo escolar em geral, está intimamente relacionada ao desenvolvimento da criança, às figuras representativas desta aprendizagem (escola, professores), ambiente de aprendizagem formal, condições orgânicas, condições emocionais e estrutura familiar.

Qualquer intercorrência em um ou mais destes fatores pode influenciar, direta ou indiretamente, o processo de aquisição da aprendizagem (LOPES, 2001). A leitura, um dos processos mais complexos da aprendizagem, compreende a discriminação visual de símbolos gráficos (grafemas) por meio de um processo de decodificação que se passa na segunda unidade, só possível com um processo de atenção seletiva regulada pela primeira unidade.

Posteriormente, e ainda na mesma unidade, há que selecionar e identificar os equivalentes auditivos (fonemas) por meio de um processo de análise e transdução, de síntese e comparação, a fim de edificar a busca da significação (conjectura) e avaliar os níveis de compreensão latentes. A partir daqui, surgirá uma nova operação de equivalência que compreende a codificação, ou seja, que são executados e verificados na área da Broca, isto é, na 
terceira unidade. Dos motos neurônios superiores frontais, a linguagem interior se transformará em linguagem expressiva, por meio da oralidade, ou seja, da produção de sons articulados. É este o todo funcional que caracteriza a aprendizagem da leitura. É dentro desse conjunto funcional que se pode verificar um distúrbio ou disfunção neuropsicológica que pode, por consequência, redundar numa dificuldade de aprendizagem (FONSECA,1995).

Embora as contribuições da neuropsicologia sejam benéficas nas esferas de intervenção do psicopedagogo, este tema se torna bastante relevante em ambientes escolares, visto que, são grandes os casos de crianças que apresentam dificuldade na aprendizagem escolar, determinado por múltiplos fatores desde a gestação ao tipo de vida que eles enfrentam e os primeiros anos escolares.

A neuropsicologia é a ciência da organização cerebral dos processos mentais humanos, cujo objetivo é 'a investigação do papel de sistemas cerebrais individuais em formas complexas de atividade mental' (LURIA, 1981). Tal investigação permite aprofundar os conhecimentos psíquicos, por meio da análise das correlações entre condutas e determinadas zonas corticais.

Há concordância na literatura de que grande parte das dificuldades com as quais as crianças disléxicas se deparam ocorre no âmbito da palavra individual, em particular na aquisição de habilidades automáticas de reconhecimento de palavras, o que altera a leitura fluente (BYRNE, 1998). A neuropsicologia tem tido crescente atuação no que diz respeito à avaliação, na medida em que se reconhece a importância de se investigar e chegar a um diagnóstico a fim de viabilizar o tratamento mais adequado.

A avaliação consiste na aplicação de técnicas de entrevistas e exames quantitativos e qualitativos, através de testes envolvendo a atenção, a memória, a percepção, a linguagem e o raciocínio em pacientes de qualquer idade. Os testes são restritos e de uso exclusivo de profissionais da psicologia. Os conceitos de Luria tem sido o alicerce para o entendimento das funções cerebrais, em especial, neste caso, a compreensão das disfunções corticais.

A aprendizagem se refere a aptidão e a possibilidade que uma pessoa tem de se eleger e aprender informações, conhecer, experimentar, compreender, decodificar, agregar, armazenar, e utilizar informações provenientes do meio em que vive. Tais capacidades proporcionam a associação e a integração desses elementos aos conhecimentos que esse indivíduo possui, afiançando relacionamentos eficazes e melhor qualidade de vida (DIAS, 2003). Cabe então aos leitores serem cúmplices ou críticos em relação às diferentes maneiras de interpretação da realidade e de intervenção sobre ela. (BOURDIEU, 1998). 


\section{CONCLUSÃO}

Mediante a esta revisão de literatura fica claro que a concepção científica da leitura deficiente predominante é, portanto, uma concepção em termos de déficit no processamento fonológico. A compreensão dos modelos mentais utilizados na

\section{REFERÊNCIAS}

Bourdieu, P. (1998). A economia das trocas linguísticas (2a ed., S. Miceli e cols., Trads.). São Paulo: Ed. USP.

BYRNE, B., \& FIELDING-BARNSLEY, R. (1989) Phonemic awareness and letter knowledge in the child's acquisitions of the alphabetic principle. Journal of Educational Psychology 81(1), 313-321.

Correia, M. F. B. \& Campos, H. (2000). Psicologia escolar: Histórias, tendências e possibilidades. Em O. H. Yamamoto e A. Cabral Neto (Orgs), O psicólogo e a escola (pp. 59-97). Natal, RN: EDUFRN.

DEUSCHLE, P.; CECHELLA, C. V. O deficit em consciência fonológica e sua relação com a dislexia: Diagnóstico e intervenção. Rev CEFAC, v.11, Supl2, p. 194-200, 2009.

Fonseca, V. (1995). Introdução às dificuldades de aprendizagem. Porto Alegre: Artes Médicas.

Formighieri, F. S. M.; Oliveira, D. E.; Sbardelotto. A dislexia e a dificuldade na aprendizagem. In: Anais do $13^{\circ}$ Encontro Científico Cultural Interistitucional, 2015. Disponível em

$<$ www.nucleodoconhecimento.com.br/edu cacao/dislexia-dificuldade-aprendizagem $>$. Acesso em: 20 de fev. 2020. compreensão do sujeito com o mundo ajuda o processo de aprendizagem quando se pode através deste conhecimento, utilizar métodos e estratégias variadas para que o cérebro possa absorver com maior qualidade as informações, afiançando assim que a aprendizagem seja garantida.

LURIA, A. R. Fundamentos de neuropsicologia. São Paulo: Edusp, 1981.

PERFETTI, C.A. (1992). A capacidade para a leitura. In: STERNBERG, R. $A s$ capacidades intelectuais humanas: uma abordagem em processamento de informações. Porto Alegre: Artes Médicas.

Quirós, J. B.; Della Cella, M. (1972). La dislexia en la niñez (3a ed.). Buenos Aires: Editorial Paidos.

SHAYWITZ, B.A.; SHAYWITZ, S.E.; PUGH, K.R.; MENCI, W.E.; FULBRIGHT, R.K.; SKIDLARSKI, P. Disruption of posterior brain systems for reading in children with developmental dyslexia.Biol Psychiatry, v. 52, p. 101-110, 2002.

TRIVIÑOS, A. N. S. Introdução à pesquisa em ciências sociais: a pesquisa qualitativa em Educação. São Paulo: Atlas, 1987.

WAGNER, R.K.; TORGESEN, J.K. The nature of Phonological Processing and Its Causal Role in the Acquisition of Reading Skills. Psychological Bulletin, v. 101, n. 2, p. 192-212, 1987. 